\title{
Development of an Immunoassay for Detection of Torque Teno Virus (TTV) Antibodies Using the N22 Expression Product from TTV Genotype 2
}

\author{
Dhananjay Singh Mankotia Mohammad Irshad \\ Clinical Biochemistry Division, Department of Laboratory Medicine, All India Institute of Medical Sciences, \\ New Delhi, India
}

\section{Keywords}

Torque teno virus · Immunoassay · Liver diseases .

Antibodies · Genotype $\cdot$ Recombinant proteins

\begin{abstract}
Aims: This study describes an immunoassay to detect antitorque teno virus (TTV) antibodies using a peptide obtained from expression of the N22 region of TTV genotype 2. Methods: The N22 region ( $500 \mathrm{bp}$ ) of TTV genotype 2 was cloned in a pET-28a(+) vector and expressed in ZYM-5052 autoinduction medium. Following metal affinity chromatography, a purified polypeptide was used as an antigen for the development of an immunoassay to detect anti-TTV antibodies in human sera. Results: Recombinant protein $(\sim 25-\mathrm{kDa})$ was obtained after $24 \mathrm{~h}$ of incubation at $25^{\circ} \mathrm{C}$ in ZYM- 5052 autoinduction medium. A blot assay developed using this polypeptide as an antigen and TTV-positive sera as the primary antibody produced a distinct spot on the nitrocellulose membrane. Serum samples from 36 of 42 patients with renal disease and 29 of 48 patients with liver diseases produced a positive signal using this immunoassay. Simultaneously, 18 of 48 healthy controls were also detected to be positive for anti-TTV antibodies. These results were found to be compa-
\end{abstract}

rable with TTV detection using PCR, and the assay showed a high sensitivity and specificity (i.e., 97.44 and $91.67 \%$, respectively). Moreover, this assay could detect TTV infection irrespectively of the genotype, including cases of mixed infection. Conclusion: The present immunoassay using the $\mathrm{N} 22$ expression product may be used as an alternative to PCR to detect TTV infection in large populations.

두 2018 S. Karger AG, Base

\section{Introduction}

Viral hepatitis affects millions of people worldwide [1]. The majority of hepatitis cases are caused by one of the known hepatitis viruses, i.e., hepatitis virus A, B, C, D, or E. However, in $5-15 \%$ of hepatitis cases, the causal agent is not known [2]. In the search for as yet unidentified hepatitis viruses, the torque teno virus (TTV) was found in 1997 in Japan in the serum of a patient with posttransfusion hepatitis of unknown etiology. A clone of approximately $500 \mathrm{nt}$, named N22, was obtained using representational differential analysis. It showed no similarity with any sequences deposited in databases [3]. Initial studies on this virus suspected it to be one of the agents

\section{KARGER}

(C) 2018 S. Karger AG, Basel

E-Mail karger@karger.com

www.karger.com/int
Dr. Mohammad Irshad

Clinical Biochemistry Division, Department of Laboratory Medicine

All India Institute of Medical Sciences, Ansari Nagar

New Delhi 110029 (India)

E-Mail drirshad54@yahoo.com 
responsible for causing non-A-E viral hepatitis. However, later studies could not corroborate this claim [4]. Further studies showed TTV to be a small nonenveloped virus containing a circular single-stranded negative-sense DNA genome about $3.8 \mathrm{~kb}$ in size [5]. Based on its genome structure, it was later renamed torque teno virus (Latin torques, i.e., "necklace", and tenuis, i.e., "thin"). TTV is presently classified in the family Anelloviridae [6, 7], which also contains other small emerging infectious agents like torque teno mini virus [8] and torque teno midi virus [9]. All of these viruses exhibit a high prevalence, a global distribution, and a high genetic variability $[10,11]$. The genetic variation represents the basis for the current classification of TTV isolates into more than 40 genotypes ( $>30 \%$ nucleotide divergence) and 5 genogroups ( $>50 \%$ nucleotide divergence) by use of phylogenetic analysis [12-14]. These numbers are continuing to increase with the introduction of new molecular techniques of higher sensitivity.

Whereas genogroups 1 and 3 are the most common globally, genogroup 2 is detected quite rarely [15]. Persistent infections and coinfections with multiple genotypes/ genogroups are noted frequently [16]. Earlier studies have demonstrated that different genetic variants are antigenically distinct. However, it is not clear whether these variants have some biological or pathogenic differences also [15]. Of course, few recent reports point to an association between genotypes/genogroups and the type of disease caused $[17,18]$. This needs further extensive investigation. TTV shows a high prevalence both in healthy and in diseased individuals globally [19-21]. The virus has been detected in nearly all tissues of the body [22]. Several studies point towards its association with liver and renal diseases [23-25]. It has also been detected in various types of carcinoma including leukemia and colorectal cancer. However, the pathogenicity of TTV at present is unclear $[7,18,20,26,27]$. Due to the lack of available tissue-culture methods, TTV infection is often diagnosed on the basis of TTV-DNA detection by PCR. This notwithstanding, it is difficult to find a universal primer set for all existing TTV genotypes [28, 29]. Although some serological methods have been devised, they are not used extensively. As a result, many aspects of the natural history of the virus, including the frequency with which acute infection leads to viral clearance, remain poorly defined.

An immunoassay to detect TTV infection in human sera was reported from our Centre [30]. It was developed using the N22 region from TTV genotype 1 and showed promising results. In the present study, we aimed to de- velop an immunoassay for detection of anti-TTV antibodies in human sera using the N22 region of TTV genotype 2 and compare its efficacy and performance with the previously developed immunoassay from TTV genotype 1. With this aim, the full-length $\mathrm{N} 22$ region was cloned in an expression vector and used to produce recombinant protein in Escherichia coli host cells. The expressed peptide was purified and used to develop a dot blot assay. Using sera from patients with liver and renal disorders as a source of primary antibody, the developed immunoassay was used to analyze the prevalence of anti-TTV antibodies in patients' sera.

\section{Materials and Methods}

The material and methods, as well as the overall workflow used in this study, are described in our previous report [30]. The complete study plan was approved by the Ethics Committee of the All India Institute of Medical Sciences, New Delhi, India.

\section{Serum Samples}

Ninety patients coming for treatment to the All India Institute of Medical Sciences were recruited for this study after informed consent. All of these patients were in the adult age group (22-43 years), from both the sexes, and they were diagnosed with acute viral hepatitis, chronic viral hepatitis, fulminant hepatic failure, or chronic kidney disease on the basis of accepted clinical and biochemical criteria. In addition, 48 sex-matched healthy subjects were also enrolled as controls. From each subject, $6-10 \mathrm{~mL}$ venous blood was drawn and collected in plain tubes. Serum was separated from blood after centrifugation and then stored at $-80^{\circ} \mathrm{C}$ until further use.

\section{Amplification of the N22 Region from Genotype 2}

Based on the nucleotide sequence of the JA1 isolate of TTV available in the GenBank database (accession No. AF122916), the full-length N22 region from TTV genotype 2 was synthesized commercially as a gBlocks ${ }^{\mathrm{TM}}$ gene fragment (Integrated DNA Technologies, USA). Primers corresponding to the above sequence were also obtained from the same commercial source: forward primer 5 '-CGCTCGGATCCATGTCATACTTTG-3', with a BamHI restriction site (underlined), and reverse primer $5^{\prime}$-CACTTGAGCTCTTACCACACCCACTT- $3^{\prime}$, with an SacI restriction site (underlined). Both primers were assessed using JustBio (www.justbio.com) and Primer3 software (http://primer3. ut.ee/). PCR amplification was performed using a Taq PCR Core Kit (Qiagen, Germany). Each $25-\mu \mathrm{L}$ reaction contained $1 \times \mathrm{Q}$-buffer, $1 \times$ PCR buffer, $200 \mu \mathrm{M}$ of each dNTP, $0.5 \mu \mathrm{M}$ of each primer, $2 \mathrm{mM} \mathrm{MgCl}_{2}$, and $0.75 \mathrm{U}$ of Taq polymerase. The PCR cycles consisted of $94^{\circ} \mathrm{C}$ for $5 \mathrm{~min}$ and 35 cycles of $94^{\circ} \mathrm{C}$ for $30 \mathrm{~s}, 52^{\circ} \mathrm{C}$ for $45 \mathrm{~s}$, and $72{ }^{\circ} \mathrm{C}$ for $45 \mathrm{~s}$, followed by a final extension at $72^{\circ} \mathrm{C}$ for $5 \mathrm{~min}$. The amplification products were resolved on $1.5 \%$ agarose gel using electrophoresis and identified as an approximately 500bp band after visualization of the gel under UV light. It was excised from the gel and extracted using a QIAquick Gel Extraction Kit (Qiagen). 
Cloning in an Expression Vector

A pET-28a(+) expression vector (Novagen, Germany) containing hexahistidine tag was selected for expression purposes. The extracted PCR product and pET-28a(+) vector were digested sequentially using the restriction enzymes BamHI and SacI (New England Biolabs, USA) at $37^{\circ} \mathrm{C}$ for $1 \mathrm{~h}$ to produce sticky (cohesive) ends. This was followed by ligation of the vector with amplicon. The reaction contained digested vector and digested insert DNA in a 1:3 ratio along with 3 Weiss units of T4 DNA Ligase (Promega Corporation, USA) and was incubated overnight at $16^{\circ} \mathrm{C}$. The resulting recombinant plasmids were transformed into $E$. coli DH5acompetent cells (Invitrogen, USA) via the heat shock method and screened on LB-agar medium plates containing $50 \mu \mathrm{g} / \mathrm{mL}$ kanamycin (Sigma-Aldrich, USA). Insertion was confirmed by colony PCR and nucleotide sequencing, as described in our previous publications [30-32]. Database searches were performed using the BLAST program (www.ncbi.nlm.nih.gov/BLAST) of the National Center for Biotechnology Information (NCBI). Plasmid from selected recombinant clones was extracted using a Qiagen Plasmid Mini Kit (Qiagen) and further checked for correct insertion of the target sequence using restriction digestion and electrophoresis on $1.2 \%$ agarose gel.

\section{Prokaryotic Expression of the N22 Protein}

The resulting recombinant expression vector was retransformed into E coli BL21 (DE3)-competent cells (Invitrogen) for expression of the recombinant protein containing the His tag (His6-G2N22-pET-28a). Transformants obtained on LB-agar plates containing kanamycin were screened for production of the target protein, and the colony showing the best yield was selected for further steps. The selected colony was cultured in a defined growth medium (MDG) at $37^{\circ} \mathrm{C}$ and grown to saturation. This starter culture (in a 1:500 dilution) was used to inoculate $100 \mathrm{~mL}$ of ZYM-5052 autoinduction growth medium [33] containing kanamycin $(100 \mu \mathrm{g} / \mathrm{mL})$ and grown in baffled flasks at $25^{\circ} \mathrm{C}$ with shaking at $225 \mathrm{rpm}$. The standard measure of culture growth was optical density at $600 \mathrm{~nm}\left(\mathrm{OD}_{600}\right)$ after dilution in water to concentrations that gave readings below 0.40 in a $1-\mathrm{cm}$ path-length cuvette in a BioTek PowerWave XS spectrophotometer. To assess the time course of protein production, aliquots corresponding to a 1-OD cell density were drawn at regular intervals and processed as described in our previous study [30]. A parallel setup containing untransformed BL21 (DE3) cells without the expression vector was used as a control experiment and processed under similar conditions. Cell lysates were analyzed on $12 \%$ SDS-PAGE using standard procedures, followed by Coomassie Brilliant Blue staining to visualize the protein bands.

\section{Immunoblotting}

Confirmation of the expressed peptide was also done using Western blotting. Proteins separated by SDS-PAGE were transferred to a nitrocellulose membrane [34], blocked in 3\% BSA, and treated with a 1:500 dilution of His probe (H-3) mouse monoclonal IgG antibody (Santa Cruz Biotechnology, USA). Horseradish peroxidase (HRP)-conjugated anti-mouse IgG antibody $(1: 2,000$; Santa Cruz Biotechnology) was used as a secondary antibody and the membrane was treated with substrate solution $(0.05 \%$ diaminobenzidine [DAB] and $0.015 \% \mathrm{H}_{2} \mathrm{O}_{2}$ in $10 \mathrm{mM}$ PBS, pH 7.2).

\section{Purification of the Recombinant Protein}

The recombinant protein was expressed on a large scale by culturing the selected clone in $500 \mathrm{~mL}$ ZYM-5052 medium for $24 \mathrm{~h}$ at $25^{\circ} \mathrm{C}$. Cells were harvested, lysed by sonication, and analyzed on SDS-PAGE to determine the solubility and localization of the expressed peptide, as described earlier [30]. Protein purification was performed using nickel-nitrilotriacetic acid (Ni-NTA) metal affinity chromatography columns (QIAexpress Kit, Qiagen) under denaturing conditions. Urea $(8 \mathrm{M})$ was used to solubilize proteins present in inclusion bodies and the lysate obtained was incubated with Ni-NTA agarose for $30 \mathrm{~min}$ at room temperature with gentle agitation. The lysate was loaded into an empty column and the flow-through fraction comprising unbound proteins was collected. To remove nonspecific proteins bound to the matrix, the column was washed with 2 bed volumes of wash buffer $(100 \mathrm{mM}$ $\mathrm{NaH}_{2} \mathrm{PO}_{4}, 10 \mathrm{~mm}$ Tris- $\mathrm{Cl}$, and $8 \mathrm{M}$ urea, $\mathrm{pH}$ 6.3). The hexahistidine ( $6 \times$ His)-tagged recombinant protein was eluted from the column by reducing the $\mathrm{pH}$ to 4.5 . All of the fractions obtained were analyzed on $12 \%$ SDS-PAGE after protein estimation [35].

\section{Development of the Dot Blot Assay}

For development of the dot blot assay, strips $(50 \times 5 \mathrm{~mm})$ of nitrocellulose membrane were used. Each strip was coated with 4 $\mu \mathrm{g}$ purified protein as antigen. After blocking the strips overnight at $4{ }^{\circ} \mathrm{C}$ in $3 \%$ BSA, dilutions of human sera in PBS $(1: 500 ; 1: 1,000$; $1: 2,000 ; 1: 3,000$; and 1:5,000) were used as the primary antibody and incubated at room temperature for $2 \mathrm{~h}$. A known TTV DNAnegative serum sample $[30,32]$ was used in the negative control strip. After washing the strips in PBS, they were incubated for $2 \mathrm{~h}$ at room temperature in goat-raised anti-human IgG-HRP-conjugated secondary antibody (1:4,000; Santa Cruz Biotechnology). One positive control strip coated with purified protein and treated with His probe (H-3) mouse monoclonal IgG antibody, followed by incubation in HRP-conjugated anti-mouse IgG secondary antibody, was also tested. All strips were developed with DAB substrate solution, as detailed earlier. The development of color in the coated region of the strips confirmed the binding of anti-TTV antibodies to the expressed N22 recombinant protein.

\section{Detection of Anti-TTV Antibodies in Human Sera}

The immunoassay developed above was used to detect antiTTV antibodies in a panel of sera from liver and renal disease patients as well as healthy individuals. Sera were tested at a dilution of 1:1,000 and the presence of anti-TTV antibodies in a serum sample was indicated by the development of a dark spot in the coated area of the NC strip after treatment with the HRP-conjugated secondary antibody and the DAB substrate solution. Several sets of sera were tested in parallel and positive and negative controls were included in all of the setups.

\section{TTV-DNA Detection Using N22 PCR}

The results of the dot blot assay were compared to detection of TTV-DNA by heminested PCR in the same panel of sera using the NG059, NG061, and NG063 primers, as described in our previous reports $[32,36]$. For this, viral nucleic acids were extracted from $200 \mu \mathrm{L}$ sera from the patient group as well as healthy controls using a High Pure Viral Nucleic Acid kit (Roche Applied Science, Germany) following the manufacturer's instructions. The extracted nucleic acids were used as a template in PCR, followed by genotyping using RFLP, as described earlier [36, 37]. The amplified products ( $271 \mathrm{bp})$ were visualized using gel electrophoresis. 


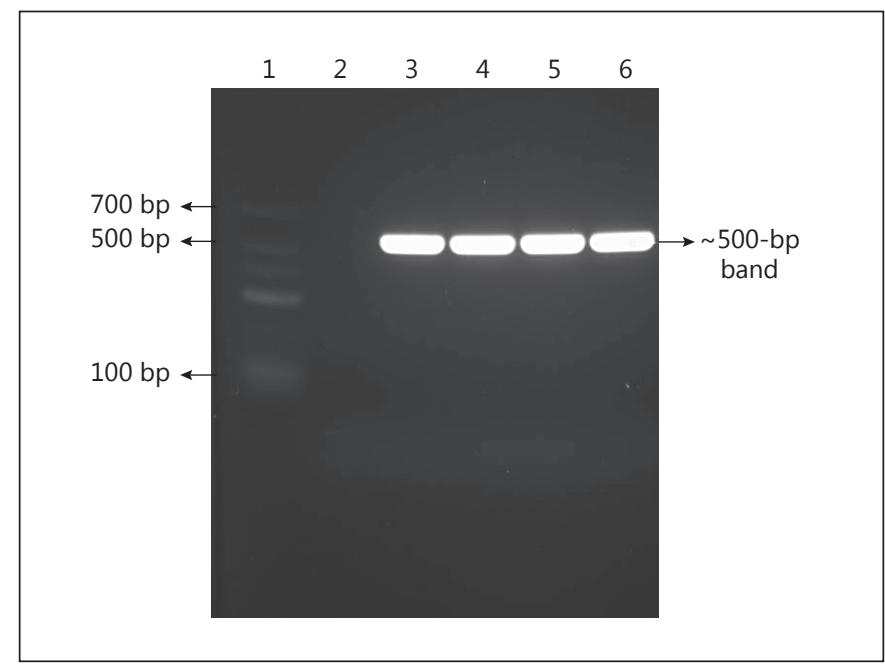

Fig. 1. Amplification of the N22 region from torque teno virus genotype 2 . Gel picture shows $\sim 500$-bp bands corresponding to the N22 region of genotype 2 obtained after PCR amplification. Amplicons were separated on 1.5\% agarose gel. Lane 1, low range DNA marker; lane 2, no template control; lanes 3-6, PCR reactions using the gBlocks ${ }^{\mathrm{TM}}$ gene fragment as a template.

\section{Comparison of the Developed Assay with the G1-N22 Blot}

Assay

The assay developed in this study was also compared to the dot blot assay using the N22 region from TTV genotype 1 (G1-N22), already developed and reported by our center [30]. The same panel of sera described earlier was assessed using the G1-N22 blot assay as well. The sensitivity and specificity of both the G1-N22 and the G2-N22 blot assays (relative to the PCR method) were calculated using the following formulae: sensitivity $=\mathrm{TP} /(\mathrm{TP}+\mathrm{FN}) \times$ 100 (where TP is the true positive and $\mathrm{FN}$ is the false negative) and specificity $=\mathrm{TN} /(\mathrm{FP}+\mathrm{TN}) \times 100$ (where $\mathrm{TN}$ is the true negative and $\mathrm{FP}$ is the false positive). A pairwise sequence comparison (global) was done with the EMBOSS Needle tool (https://www.ebi. ac.uk/Tools/psa/) using the default settings. Vector contamination in the sequences was identified using the VecScreen tool (https:// www.ncbi.nlm.nih.gov/tools/vecscreen/) of NCBI.

\section{Results}

\section{Amplification and Cloning of N22 Region}

Amplification of the full-length N22 region from TTV genotype 2 using a commercially obtained gBlocks ${ }^{\mathrm{TM}}$ gene fragment as a template for PCR was done successfully. Primers used corresponded to nucleotides 1832 2333 of JA1, a known genotype 2 isolate of TTV. Gel electrophoresis of the amplification products demonstrated a clear band ( $\sim 500 \mathrm{bp})$ on the agarose gel (Fig. 1). This band was excised from the gel and purified using a com- mercial kit. The amplicon ( $500 \mathrm{bp})$ along with the pET$28 \mathrm{a}(+)$ expression vector were digested using $\mathrm{BamHI}$ and SacI restriction enzymes. This was aimed to generate cohesive ends to facilitate directional cloning of the DNA sequence corresponding to the N22 region into the expression vector. The digestion products were ligated, transformed in E. coli host cells, and screened on LB-agar plates containing kanamycin. The positive colonies obtained were subjected to colony PCR, which revealed a band ( $500 \mathrm{bp})$ on agarose gel indicating successful insertion of the DNA sequence. The cloned recombinant plasmid was isolated from positive colonies and digested using BamHI and SacI restriction enzymes. Gel electrophoresis of the digestion products demonstrated the presence of bands ( $\sim 0.5$ and $\sim 5.4 \mathrm{~kb})$ on agarose gel corresponding to the DNA insert and expression vector, respectively. Bidirectional sequencing on an automated sequencer also confirmed the nucleotide sequence and orientation of the N22 insert in the recombinant expression vector. BLAST analysis of the sequence revealed $99 \%$ identity with nucleotide sequences of the JA1 isolate of TTV.

\section{Prokaryotic Expression of the N22 Protein}

Expression of the recombinant protein was performed in the E. coli BL21 (DE3) strain. Screening of colonies revealed expression of an approximately $25-\mathrm{kDa}$ recombinant protein. The colony showing the best yield was used to assess the time course of the protein production and further large-scale expression. The primary culture in MDG growth medium followed by subculturing in ZYM5052 autoinduction medium and a run on SDS-PAGE gel revealed overexpression of the approximately $25-\mathrm{kDa}$ recombinant protein after $24 \mathrm{~h}$ of incubation at $25^{\circ} \mathrm{C}$ (Fig. 2a). No expression of approximately $25 \mathrm{kDa}$ protein was seen in the control setup containing host cells without the recombinant plasmid. Western blot analysis using a commercial anti-His antibody (His probe) as the primary antibody also revealed a band $(\sim 25 \mathrm{kDa})$ in the lane with lysate from E. coli BL21 (DE3) cells harboring the recombinant vector and no protein band in the lane with lysate from the control setup, i.e., host cells without the recombinant vector, as shown in Figure $2 \mathrm{~b}$. This further supports our findings on the successful expression of the approximately $25-\mathrm{kDa}$ protein.

\section{Protein Purification}

Large-scale expression was performed and the harvested bacterial cells were lysed by sonication and the expressed recombinant protein was retrieved in the insolu- 


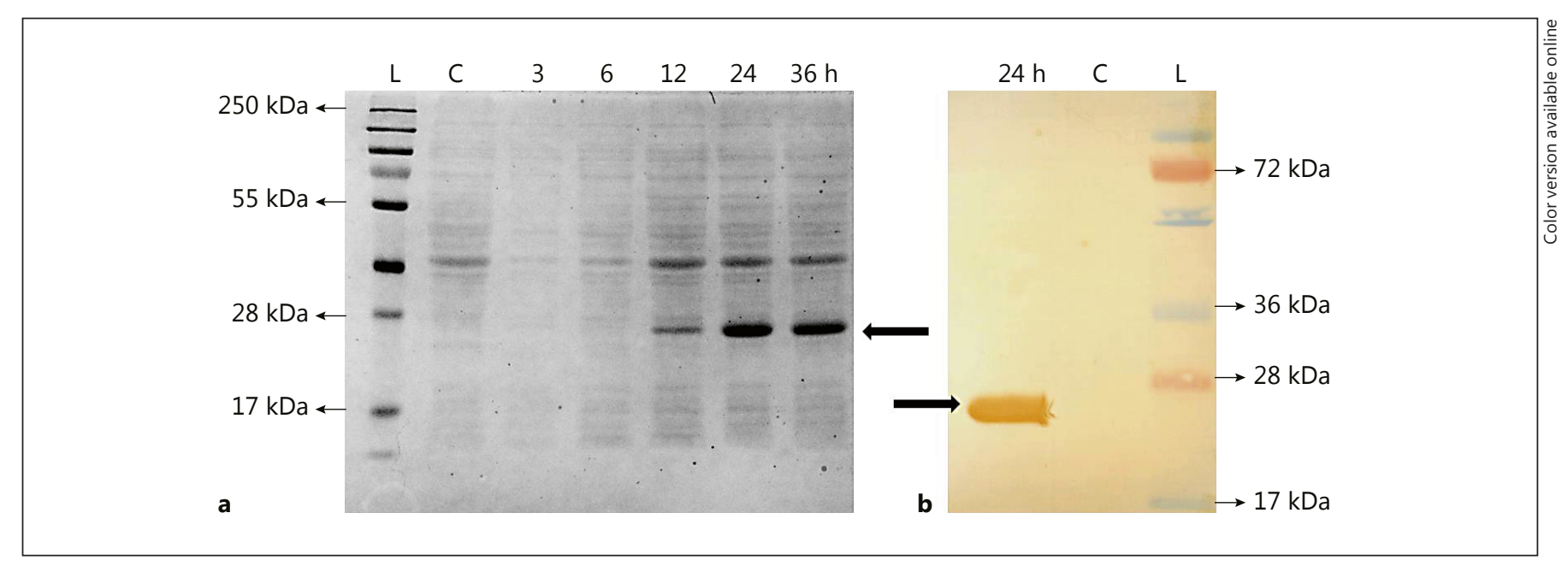

Fig. 2. Expression of recombinant protein in ZYM-5052 autoinduction medium. a Coomassie-stained 12\% SDS-PAGE gel shows the time course of the production of $\sim 25-\mathrm{kDa} \mathrm{N} 22$ protein in ZYM-5052 growth medium incubated at $25^{\circ} \mathrm{C}$. Each lane contains lysates from equal amount of cells (each corresponding to $1 \mathrm{OD}_{600}$ cell density). The control lane contains untransformed cells without vector, grown in similar conditions. Lane L, protein marker; lane C, control; lanes 3-36 h, lysates from cells aliquoted at differ- ent time intervals, as indicated on top of each lane. b Western blot of the expressed protein. The expressed protein was transferred to a nitrocellulose membrane, blocked in 3\% BSA, treated with primary and secondary antibodies, and developed with DAB. Lane 24 $\mathrm{h}$, lysate from the 24-h culture; lane $\mathrm{C}$, control; lane $\mathrm{L}$, protein marker. Bold arrows denote $\sim 25-\mathrm{kDa}$ bands corresponding to the expressed recombinant protein.

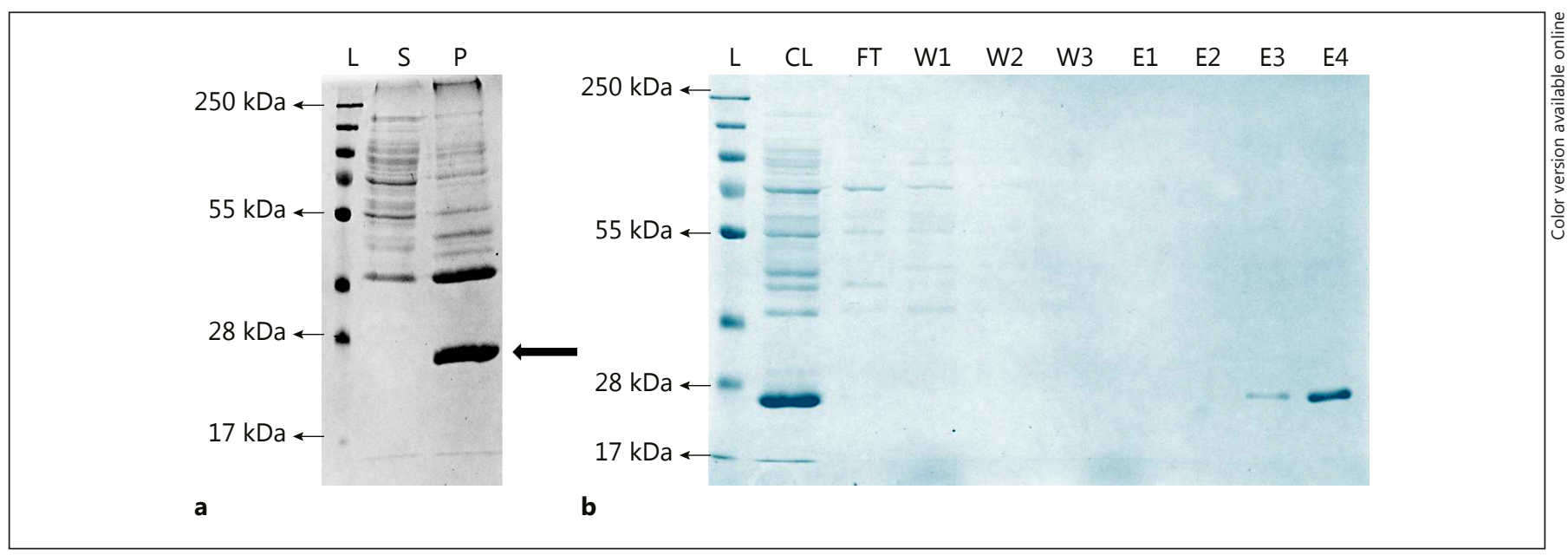

Fig. 3. Solubility testing and purification of the expressed recombinant protein. a Coomassie-stained $12 \%$ SDS-PAGE of soluble and insoluble fractions. The bold arrow denotes the expressed recombinant protein. Lane L, protein marker; lane S, protein from the soluble fraction; lane $\mathrm{P}$, protein from the pellet/insoluble fraction. $\mathbf{b}$ Coomassie-stained $12 \%$ SDS-PAGE of various fractions ob-

ble fraction of the cell lysate. Figure 3 a shows the presence of a band $(\sim 25 \mathrm{kDa})$ in the pellet/insoluble fraction on the Coomassie-stained SDS-PAGE gel. Protein aggregates were solubilized using $8 \mathrm{M}$ urea and protein was purified tained during protein purification using nickel-nitrilotriacetic acid columns. Lane L, protein marker; lane CL, cleared lysate; lane FT, flow-through fraction; lanes W1-W3, wash fractions 1-3; lanes E1-E4, elution fractions 1-4. Protein from elution fractions 3 and 4 was pooled and used in the immunoassay.

using Ni-NTA agarose columns in the presence of this strong denaturing agent. Various fractions obtained were run on SDS-PAGE gel. As shown in Figure 3b, only nonspecific proteins were detected in the flow-through and 


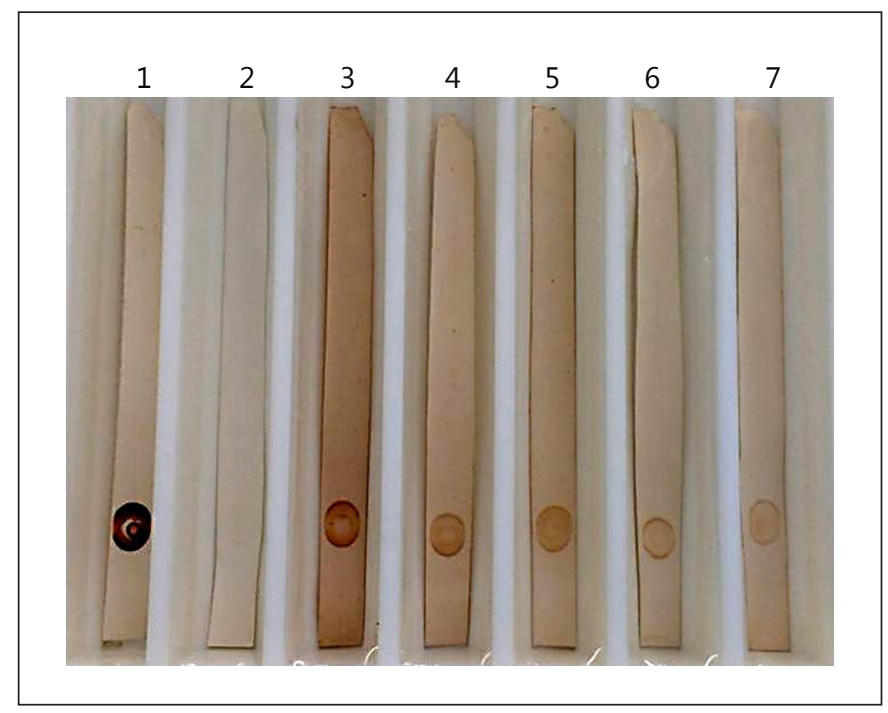

Fig. 4. Dot blot assay using human sera. Dilutions of sera in PBS were used as the primary antibody. The positive control indicates a strip tested with anti-His antibody. A known torque teno virusnegative serum sample was used as the negative control. Strip 1, positive control; strip 2, negative control; strip 3, 1:500 serum dilution; strip 4, 1:1,000 serum dilution; strip 5, 1:2,000 serum dilution; strip 6, 1:3,000 serum dilution; strip 7: 1:5,000 serum dilution.

wash fractions. Most of the recombinant protein bound efficiently to the column due to affinity between histidine residues and $\mathrm{Ni}^{2+}$ residues. The band of approximately 25 $\mathrm{kDa}$ in the lanes corresponding to the elution fractions confirms the purification of the target protein.

\section{Dot Blot Assay for Anti-TTV Antibodies}

Elution fractions showing a good intensity of recombinant protein were pooled and used to coat strips of nitrocellulose membrane to develop a dot blot assay for the detection of anti-TTV antibodies. Initially, serum from a known TTV-positive sample was used in various dilutions to optimize the assay and determine the appropriate dilution of sera for the successful detection of anti-TTV antibodies. As illustrated in Figure 4, 1:1,000 dilution was found to be the optimal dilution for the detection of antiTTV antibodies. No spot could be observed in a negative control strip which was processed with a known TTVnegative serum sample obtained from a healthy donor. Based on this assay, a panel of sera from 90 patients with different liver and kidney diseases and 48 healthy subjects was analyzed for the presence of anti-TTV antibodies. The results of the dot blot assay were compared to the presence of TTV-DNA using N22 PCR (Table 1). We observed a correlation between TTV-DNA and anti-TTV antibodies
Table 1. Comparison of PCR with the developed dot blot assay

\begin{tabular}{|c|c|c|c|c|c|}
\hline \multirow[t]{2}{*}{ Group } & \multirow[t]{2}{*}{$\begin{array}{l}\text { Tested }^{1}, \\
\end{array}$} & \multicolumn{2}{|c|}{ PCR positivity ${ }^{2}$} & \multicolumn{2}{|c|}{$\begin{array}{l}\text { G2-N22 dot blot } \\
\text { assay positivity }^{3}\end{array}$} \\
\hline & & $n$ & $\%$ & $n$ & $\%$ \\
\hline \multicolumn{6}{|l|}{ Chronic kidney } \\
\hline disease & 42 & 34 & 81.0 & 36 & 85.7 \\
\hline Liver diseases ${ }^{4}$ & 48 & 27 & 56.3 & 29 & 60.4 \\
\hline Healthy controls & 48 & 17 & 35.4 & 18 & 37.5 \\
\hline
\end{tabular}

${ }^{1}$ Patients as well as healthy controls were tested. ${ }^{2}$ Torque teno virus DNA detection using N22 PCR. ${ }^{3}$ Anti-TTV antibody detection using G2-N22 dot blot assay. ${ }^{4}$ Includes patients infected with acute viral hepatitis, chronic viral hepatitis, and fulminant hepatic failure.

Table 2. Determination of sensitivity and specificity

\begin{tabular}{lllcc}
\hline & \multirow{2}{*}{ Result } & \multicolumn{2}{c}{ PCR method } & \multirow{2}{*}{ Total } \\
\cline { 3 - 4 } & & positive & negative & \\
\hline G2-N22 & positive & 76 & 5 & 81 \\
blot assay & negative & 2 & 55 & 57 \\
\hline & total & 78 & 60 & 138 \\
\hline Sensitivity $^{1}$ & $97.44 \%(95 \%$ CI 91.04-99.69) & \\
Specificity $^{2}$ & $91.67 \%(95 \%$ CI 81.61-97.24) & \\
\hline
\end{tabular}

${ }^{1}$ Calculated as: $\mathrm{TP} /(\mathrm{TP}+\mathrm{FN}) \times 100 .{ }^{2}$ Calculated as: $\mathrm{TN} /(\mathrm{FP}+$ TN) $\times 100$.

in this panel of sera. As shown in the Table 1, TTV infection was observed in 36 out of 42 (85.7\%) patients with chronic kidney disease and 29 out of 48 (60.4\%) patients with liver diseases, respectively. Eighteen out of 48 (37.5\%) healthy individuals also showed the presence of this virus.

\section{Comparison with the G1-N22 Blot Assay}

The sensitivity and specificity of the blot assay in comparison to the PCR method were calculated using the formulae described earlier. As shown in Table 2, out of a total of 138 sera, only 2 sera were found to be false negatives, while 5 cases were reported as false positives. The sensitivity was found to be $97.44 \%$ (95\% CI 91.04-99.69), while the specificity was $91.67 \%$ (95\% CI 81.61-97.24). These values were comparable to the sensitivity and specificity of the G1-N22 blot assay in the same panel of sera and were found to be 98.72 (95\% CI 93.06-99.97) and 90.00\% (95\% CI 79.49-96.24), respectively. 
Table 3. Genotype specificity of the blot assays

\begin{tabular}{llll}
\hline $\begin{array}{l}\text { Genotype status } \\
\text { of sera }^{1}\end{array}$ & $\begin{array}{l}\text { Tested } \\
\text { patients } \\
n\end{array}$ & $\begin{array}{l}\text { G1-N22 } \\
\text { dot blot } \\
\text { positivity }\end{array}$ & $\begin{array}{l}\text { G2-N22 } \\
\text { dot blot } \\
\text { positivity }\end{array}$ \\
\hline $\begin{array}{l}\text { Genotype 1 } \\
\text { Genotype 2 }\end{array}$ & 54 & 54 & 54 \\
Mixed infection $^{5}$ & 5 & 5 & 5 \\
TTV positive $^{6}$ & 7 & 7 & 6 \\
\hline
\end{tabular}

TTV, torque teno virus. ${ }^{1}$ Based on RFLP genotyping [35]. ${ }^{2}$ Sera from healthy controls showing presence of TTV were also tested. ${ }^{3}$ Sera showing a positive signal when tested with the dot blot assay developed using the N22 region from TTV genotype 1. ${ }^{4}$ Sera showing a positive signal when tested with the dot blot assay developed using the N22 region from TTV genotype $2 .{ }^{5}$ Cases with presence of 2 different TTV genotypes in the same sample. ${ }^{6}$ Cases in which genotyping could not be conducted successfully.

We also assessed the genotype specificity of the dot blot assay developed in this study and compared it with G1-N22 blot assay. Genotyping of PCR-positive cases revealed the presence of only TTV genotypes 1 and 2 in the study population, while few cases of mixed infection were also recorded. The results, as depicted in Table 3, clearly show that the immunoassay was equally effective in detecting anti-TTV antibodies in sera, irrespective of the genotype status of the serum samples. Cases from TTV genotypes 1 and 2, as well as cases of mixed infection, could be detected using both assays with equal efficiency. It may be concluded that either assay could be used for the detection of anti-TTV antibodies in human sera for the diagnosis of TTV infection. The nucleotide sequences coding for the expressed N22 peptides from both genotypes 1 and 2 were analyzed after the identification and removal of vector contamination in the sequences. Pairwise sequence alignment using EMBOSS Needle revealed $74.5 \%$ identity between the two sequences.

\section{Discussion}

TTV, characterized in 1997 [3] and found in later studies to be an apparently benign virus causing little harm to human beings, has intrigued researchers for almost two decades. As such, TTV is globally prevalent and has often been noticed in the blood of even healthy individuals in a very high proportion $[17,21]$. Firstly a high prevalence rate and secondly the highly heterogeneous nature of its DNA have raised a serious concern. Simultaneously, it is quite interesting to note an association of TTV with certain carcinomas/malignancies, indicating the chances of its DNA integrating with the human genome during the replication cycle [18]. However, no such conclusive report is available at this stage and therefore further studies on various aspects of this virus, including its role in disease causation, are required [20,38].

The present study was planned with the sole objective of developing an immunoassay to detect the presence of TTV in human sera. Although the detection of TTVDNA in serum by PCR is often used to diagnose TTV infection, an advanced infrastructure and expertise are required for conducting the tests. Diagnostic laboratories with such infrastructure and skilled manpower are still lacking in many parts of the world, especially in developing countries. Moreover, due to the highly heterogeneous nature of TTV-DNA, no single primer set is sufficient to detect all genotypes and subtypes of TTV [29]. Therefore, it was realized that a simple immunoassay system is a comparatively more feasible, simple, and cost-effective method for use in routine diagnostic centers.

Our previous report describes cloning and expression of the N22 region from TTV genotype 1 and use of the expression product as a potential antigen to detect antiTTV antibodies [30]. In the present study, a similar approach was used to clone and express the N22 region from TTV genotype 2 as well. In fact, genotype 2 has been reported to be more pathogenic compared to other genotypes [19]. The present plan aimed to investigate the antigenic potential of peptide expressed by the N22 region of TTV genotype 2 and use it to develop an immunoassay for more studies on TTV detection. We also aimed to compare the results of this assay with the previously developed assay using the N22 region from TTV genotype 1. The N22 region is an approximately 500-nt conserved region of ORF-1 of the TTV genome. Since development of a suitable primer set for direct PCR amplification was not possible due to the high GC content and incompatible $\mathrm{T}_{\mathrm{m}}$ of the potential primer sets, the full length $\mathrm{N} 22$ region of TTV genotype 2 was synthesized commercially as a double-stranded gBlocks ${ }^{\mathrm{TM}}$ gene fragment and used as template. PCR amplification was conducted using primers corresponding to this oligonucleotide. These primers contained recognition sites for BamHI and SacI restriction endonucleases to allow directional cloning of the N22 sequence in the expression vector. A stop codon was added to the reverse primer sequence to stop the protein translation. The amplified DNA sequence was cloned into a pET-28a(+) expression vector. This vector was selected because it contains an upstream hexahistidine $(6 \times$ 
His) affinity tag which helps in purification of the protein. Cloning was confirmed by colony PCR, nucleotide sequencing, and restriction digestion of the isolated recombinant plasmid. BLAST analysis revealed a good identity of the cloned insert with sequences of known TTV isolates submitted to the NCBI database.

The recombinant protein was expressed in E. coli BL21 (DE3) host cells as a fusion protein containing the $6 \times$ His tag. Expression was conducted in ZYM-5052 autoinduction medium [33]. The use of autoinduction growth medium eliminates the need for addition of IPTG as an inducer and monitoring of the OD, which is a tedious exercise. It is also superior to LB-IPTG because the problem of leaky expression, i.e., basal expression in uninduced cultures (with no added IPTG), may be overcome by the use of this autoinduction medium [33]. We successfully used ZYP-5052 medium in our previous report [30] and observed improved yields of expressed protein as compared to LB-IPTG medium. However, in this study we used the ZYM-5052 medium instead, because it was suggested to be a better growth medium giving slightly improved yields as compared to ZYP-5052 (results not shown). At the same time, it was also found to be costeffective because it uses less antibiotic (only $100 \mu \mathrm{g} / \mathrm{mL}$ compared to $150 \mu \mathrm{g} / \mathrm{mL}$ for ZYP-5052). Expression studies revealed the production of an approximately $25-\mathrm{kDa}$ protein on the SDS-PAGE gel. The best yields were obtained after culturing for $24 \mathrm{~h}$ at $25^{\circ} \mathrm{C}$. This was further confirmed by immunoblotting using anti-His antibodies.

Analysis of protein solubility and intracellular localization revealed the presence of recombinant protein in the insoluble fraction of the cell lysate, suggesting protein aggregation in insoluble inclusion bodies or coprecipitation with insoluble bacterial cell debris. The N22 protein was expressed as a recombinant protein containing the $6 \times$ His tag. This affinity tag on the recombinant proteins allows immobilization of protein on metal-chelating surfaces and this property was exploited in purification of the protein using immobilized metal affinity chromatography, where the N22 protein bound successfully to NiNTA agarose columns. The purified recombinant protein obtained was coated on strips of nitrocellulose membrane and used as antigen to develop a dot blot assay for the detection of anti-TTV antibodies. This assay was optimized for various experimental conditions. Serum from a known TTV-positive sample was tested and this produced a clear spot on the strip after development with the DAB substrate solution. No spot was observed on the strip when a known TTV-negative sample $[32,30]$ was used in the assay as the primary antibody. The present assay was used to detect anti-TTV antibodies in a panel of sera from patients with liver and renal diseases as well as healthy individuals. The results of the immunoassay were compared to those of PCR used for the detection of TTV-DNA.

We observed that the developed assay showed a high sensitivity and specificity and nearly all of the PCR-positive samples were detected using the current dot blot assay. In fact, some PCR-negative samples produced positive signals in the dot blot assay. Possibly, these false-positive samples could represent: (1) cases of past infection where the active virus was already eliminated from the body at the time of collection of the blood sample but antibodies were still prevalent in the circulatory system, (2) samples containing very low viral titers that were beyond the limit of PCR detection, or (3) cases where the primer set was unable to pick one particular strain or genotype of TTV $[14,39,40]$.

Simultaneously, we also compared this immunoassay with the previously reported dot blot assay developed using TTV genotype 1. Both G1-N22 and G2-N22 blot assays demonstrated comparable sensitivities and specificities in detecting the presence of TTV infection. It may be attributed to the high nucleotide identity between N22 sequences from genotypes 1 and 2 . We also assessed the genotype specificity of the assays by comparing the results of G1-N22 and G2-N22 blot assays with the genotype(s) of TTV present in the serum samples. TTV genotype 1 was the predominant genotype in our study population, while few cases of genotype 2 were also reported. These results are in consonance with those of previous studies from India [41, 42], including from our own center [36]. Our findings indicate that both assays were equally effective in detecting anti-TTV antibodies irrespective of the TTV genotype, possibly indicating a lack of genotype specificity of the antibodies detected. However, our reports are not adequate to support this theory, unless all genotypes of TTV are tested with the developed assays. Because only genotypes 1 and 2 were reported in our study population, we could test only these two genotypes. However, assessment of other genotypes can greatly increase the scope of the developed assays and further studies are needed in this regard. As such, our results rule out the possibility of using the above assays to differentiate between genotypes present in the serum samples. However, since our aim was to develop a simple method for screening of TTV infection and not for genotypic discrimination, the developed assay serves its purpose.

Although similar attempts were made in the past using various subgenomic regions of TTV-DNA, including ORF-1 $[40,43,44]$ and ORF-2 $[15,28,32]$; however, we 
envisaged that N22, being a conserved region, could be a better subgenomic region for use in the development of immunoassay. Furthermore, all of the studies reported so far are based on genotype 1 since it is highly prevalent globally. This is the first report on cloning, expression, and use of a sequence from TTV genotype 2 . Our findings indicate that the present assay was successful in detecting anti-TTV antibodies irrespective of the TTV genotype, while showing an efficacy comparable to that of the previously developed blot assay using the N22 region from genotype 1 . As such, the authors recommend this immunoassay for its wider use in diagnosis of TTV infection.

\section{Acknowledgements}

The authors are thankful to the Council of Scientific and Industrial Research (CSIR), New Delhi, India, for providing financial support.

\section{Disclosure Statement}

The authors declare that there are no conflicts of interests.

\section{References}

1 Stanaway JD, Flaxman AD, Naghavi M, Fitzmaurice C, Vos T, Abubakar I, et al: The global burden of viral hepatitis from 1990 to 2013: findings from the Global Burden of Disease Study 2013. Lancet 2016;388:1081-1088.

2 Satoh K, Iwata-Takakura A, Osada N, Yoshikawa A, Hoshi Y, Miyakawa K, et al: Novel DNA sequence isolated from blood donors with high transaminase levels. Hepatol Res 2011;41:971-981.

3 Nishizawa T, Okamoto H, Konishi K, Yoshizawa $\mathrm{H}$, Miyakawa $\mathrm{Y}$, Mayumi M: A novel DNA virus (TTV) associated with elevated transaminase levels in posttransfusion hepatitis of unknown etiology. Biochem Biophys Res Commun 1997;241:92-97.

4 Irshad M, Joshi YK, Sharma Y, Dhar I: Transfusion transmitted virus: a review on its molecular characteristics and role in medicine. World J Gastroenterol 2006;12:5122-5134.

5 Mushahwar IK, Erker JC, Muerhoff AS, Leary TP, Simons JN, Birkenmeyer LG, et al: Molecular and biophysical characterization of TT virus: evidence for a new virus family infecting humans. Proc Natl Acad Sci USA 1999;96: 3177-3182.

6 King AMQ: Virus Taxonomy: Classification and Nomenclature of Viruses: Ninth Report of the International Committee on Taxonomy of Viruses. London, Elsevier, 2011.

7 Zhang Y, Li F, Shan T-L, Deng X, Delwart E, Feng X-P: A novel species of torque teno mini virus (TTMV) in gingival tissue from chronic periodontitis patients. Sci Rep 2016;6:26739.

8 Takahashi K, Iwasa Y, Hijikata M, Mishiro S: Identification of a new human DNA virus (TTV-like mini virus, TLMV) intermediately related to $\mathrm{TT}$ virus and chicken anemia virus. Arch Virol 2000;145:979-993.

9 Ninomiya M, Nishizawa T, Takahashi M, Lorenzo FR, Shimosegawa T, Okamoto H: Identification and genomic characterization of a novel human torque teno virus of $3.2 \mathrm{~kb}$. J Gen Virol 2007;88:1939-1944.
10 Changani L, Bouzari M, Talebi A: Torque teno mini virus infection in chronic cervicitis and cervical tumors in Isfahan, Iran. Intervirology 2013;56:265-270.

11 Spandole S, Cimponeriu D, Berca LM, Mihăescu G: Human anelloviruses: an update of molecular, epidemiological and clinical aspects. Arch Virol 2015;160:893-908.

12 Peng YH, Nishizawa T, Takahashi M, Ishikawa T, Yoshikawa A, Okamoto H: Analysis of the entire genomes of thirteen TT virus variants classifiable into the fourth and fifth genetic groups, isolated from viremic infants. Arch Virol 2002;147:21-41.

13 Jelcic I, Hotz-Wagenblatt A, Hunziker A, Zur Hausen $\mathrm{H}$, de Villiers E-M: Isolation of multiple TT virus genotypes from spleen biopsy tissue from a Hodgkin's disease patient: genome reorganization and diversity in the hypervariable region. J Virol 2004;78:74987507.

14 Hsiao K-L, Wang L-Y, Lin C-L, Liu H-F: New phylogenetic groups of torque teno virus identified in Eastern Taiwan indigenes. PLoS One 2016;11:e149901.

15 Chen T, Väisänen E, Mattila PS, Hedman K, Söderlund-Venermo M: Antigenic diversity and seroprevalences of torque teno viruses in children and adults by ORF2-based immunoassays. J Gen Virol 2013;94:409-417.

16 Biagini P, Gallian P, Cantaloube J-F, Attoui $\mathrm{H}$, de Micco P, de Lamballerie X: Distribution and genetic analysis of TTV and TTMV major phylogenetic groups in French blood donors. J Med Virol 2006;78:298-304.

17 Bostan N: Current and future prospects of torque teno virus. J Vaccines Vaccin 2013, DOI: 10.4172/2157-7560.S1-004.

18 Hettmann A, Demcsák A, Bach Á, Decsi G, Dencs Á, Pálinkó D, et al: Detection and phylogenetic analysis of torque teno virus in salivary and tumor biopsy samples from head and neck carcinoma patients. Intervirology 2016;59:123-129.
19 Ali S, van Pelt JF, Verslype C, Nevens F, Fevery J, Yap SH: TT virus infection in acute and chronic liver diseases and in patients regularly receiving blood products in Belgium. Acta Gastroenterol Belg 2004;67:161-165.

20 Kew MC: Hepatitis viruses (other than hepatitis $B$ and $C$ viruses) as causes of hepatocellular carcinoma: an update. J Viral Hepat 2013;20:149-157.

21 Hassuna NA, Naguib E, Abdel-Fatah M, Mousa SMO: Phylogenetic analysis of torque teno virus in thalassemic children in Egypt. Intervirology 2017;60:102-108.

22 Okamoto H, Nishizawa T, Takahashi M, Asabe S, Tsuda F, Yoshikawa A: Heterogeneous distribution of TT virus of distinct genotypes in multiple tissues from infected humans. Virology 2001;288:358-368.

$23 \mathrm{Hu}$ Z-J, Lang Z-W, Zhou Y-S, Yan H-P, Huang D-Z, Chen W-R, et al: Clinicopathological study on TTV infection in hepatitis of unknown etiology. World J Gastroenterol 2002;8:288-293.

24 Irshad M, Sharma Y, Dhar I, Singh J, Joshi Y-K: Transfusion-transmitted virus in association with hepatitis A-E viral infections in various forms of liver diseases in India. World J Gastroenterol 2006;12:2432-2436.

25 Irshad M, Mandal K, Singh S, Agarwal SK: Torque teno virus infection in hemodialysis patients in North India. Int Urol Nephrol 2010;42:1077-1083.

26 de Villiers E-M, Bulajic M, Nitsch C, Kecmanovic D, Pavlov M, Kopp-Schneider A, et al: TTV infection in colorectal cancer tissues and normal mucosa. Int J Cancer 2007;121:21092112.

27 Chu CC, Zhang L, Dhayalan A, Agagnina BM, Magli AR, Fraher G, et al: Torque teno virus 10 isolated by genome amplification techniques from a patient with concomitant chronic lymphocytic leukemia and polycythemia vera. Mol Med 2011;17:1338-1348. 
28 Kakkola L, Hedman K, Vanrobaeys H, Hedman L, Söderlund-Venermo M: Cloning and sequencing of TT virus genotype 6 and expression of antigenic open reading frame 2 proteins. J Gen Virol 2002;83:979-990.

$29 \mathrm{HuY}-\mathrm{W}, \mathrm{Al}-\mathrm{Moslih}$ MI, Al Ali MT, Khameneh SR, Perkins H, Diaz-Mitoma F, et al: Molecular detection method for all known genotypes of TT virus (TTV) and TTV-like viruses in thalassemia patients and healthy individuals. J Clin Microbiol 2005;43:3747-3754.

30 Mankotia DS, Irshad M: Cloning and expression of N22 region of torque teno virus (TTV) genome and use of peptide in developing immunoassay for TTV antibodies. Virol J 2014; 11:96.

31 Ansari MA, Irshad M, Agarwal SK, Chosdol $\mathrm{K}$ : Expression of the full-length HCV core subgenome from HCV gentoype- $1 \mathrm{a}$ and genotype- $3 a$ and evaluation of the antigenicity of translational products. Eur J Gastroenterol Hepatol 2013;25:806-813.

32 Singh S, Singh A, Mankotia DS, Luthra K, Irshad M: Expression of TTV-ORF2 protein for detection of anti-TTV IgG antibodies in human sera. Adv Infect Dis 2013;03:223-229.

33 Studier FW: Protein production by auto-induction in high density shaking cultures. Protein Expr Purif 2005;41:207-234.
34 Towbin H, Staehelin T, Gordon J: Electrophoretic transfer of proteins from polyacrylamide gels to nitrocellulose sheets: procedure and some applications. Proc Natl Acad Sci USA 1979;76:4350-4354.

35 Bradford MM: A rapid and sensitive method for the quantitation of microgram quantities of protein utilizing the principle of proteindye binding. Anal Biochem 1976;72:248-254.

36 Irshad M, Singh S, Irshad K, Agarwal S-K, Joshi Y-K: Torque teno virus: its prevalence and isotypes in North India. World J Gastroenterol 2008;14:6044-6051.

37 Tanaka Y, Mizokami M, Orito E, Ohno T, Nakano T, Kato T, et al: New genotypes of TT virus (TTV) and a genotyping assay based on restriction fragment length polymorphism. FEBS Lett 1998;437:201-206.

38 Prasetyo AA, Desyardi MN, Tanamas J, Suradi, Reviono, Harsini, et al: Respiratory viruses and torque teno virus in adults with acute respiratory infections. Intervirology 2015;58:57-68.
39 Okamoto H, Takahashi M, Nishizawa T, Ukita M, Fukuda M, Tsuda F, et al: Marked genomic heterogeneity and frequent mixed infection of TT virus demonstrated by PCR with primers from coding and noncoding regions. Virology 1999;259:428-436.

40 Ott C, Duret L, Chemin I, Trépo C, Mandrand B, Komurian-Pradel F: Use of a TT virus ORF1 recombinant protein to detect anti-TT virus antibodies in human sera. J Gen Virol 2000;81:2949-2958.

41 Arankalle VA, Gandhe SS, Deshmukh TM, Chadha MS, Walimbe AM: Prevalence and phylogenetic analysis of TT virus DNA in Western India. Clin Diagn Lab Immunol 2000;7:845-849.

42 Asim M, Singla R, Gupta RK, Kar P: Clinical and molecular characterization of human TT virus in different liver diseases. Indian J Med Res 2010;131:545-554.

43 Lo SY, Peng KF, Ma HC, Yu JH, Li YH, Lin $\mathrm{HH}$, et al: Prevalence of TT virus DNA in eastern Taiwan aborigines. J Med Virol 1999;59: 198-203.

44 Handa A, Dickstein B, Young NS, Brown KE: Prevalence of the newly described human circovirus, TTV, in United States blood donors. Transfusion 2000;40:245-251. 